\title{
Growth Patterns of Signet Ring Cell Carcinoma of the Stomach for Endoscopic Resection
}

Hyunki Kim*, Jie-Hyun Kim ${ }^{t, \neq}$, Yong Chan Lee ${ }^{\dagger}$, Hoguen Kim*, Young Hoon Youn ${ }^{\dagger, \ddagger}$, Hyojin Park ${ }^{\dagger, \ddagger}$, Seung Ho Choi ${ }^{\ddagger, \S}$, Sung Hoon Noh ${ }^{\S}$, and Takuji Gotodall

Departments of *Pathology, ${ }^{\dagger}$ Internal Medicine, Yonsei University College of Medicine, ${ }^{\ddagger}$ Gangnam Severance Hospital, ${ }^{8}$ Department of Surgery, Yonsei University College of Medicine, Seoul, Korea, and "Department of Gastroenterology and Hepatology, Tokyo Medical University, Tokyo, Japan

\section{See editorial on page 695.}

Background/Aims: It is difficult to precisely detect the lateral margin during endoscopic submucosal dissection (ESD) for signet ring cell carcinoma (SRC) because SRC often expands to lateral direction through the lamina propria. Thus, the aim of this study was to classify the intramucosal spreading patterns of SRC and to analyze the patients' clinicopathological findings according to the spreading patterns. Methods: The intramucosal spreading patterns of SRC were classified as expansive or infiltrative types. A total of 100 surgical and 42 ESD specimens were reviewed. Results: In the surgical specimens, the proportions of expansive and infiltrative types were $44 \%$ and $56 \%$, respectively. The infiltrative type was more commonly associated with old age, atrophy, and intestinal metaplasia in surrounding mucosa and the absence of Helicobacter pylori compared with the expansive type. In ESD specimens, the proportions of expansive and infiltrative types were each 50\%. When lateral margin-positive lesions were compared with -negative lesions, larger size, residual lesion, and the lack of a neutrophil infiltration were more significantly associated with lateral margin-positive lesions. All cases with residual tumors in lateral margin-positive lesions were classified as the infiltrative type. Conclusions: SRC surrounded with atrophy and/or intestinal metaplasia often spreads subepithelially in the margin. This finding may suggest that a larger safety margin is necessary in this type during ESD. (Gut Liver 2015;9:720-726)

Key Words: Carcinoma, signet ring cell; Endoscopy; Resection; Stomach neoplasms

\section{INTRODUCTION}

Endoscopic resection (ER) for intramucosal lesions consisted of signet ring cell carcinoma (SRC) has been performed based on previous studies. ${ }^{1,2}$ ER in SRC has been managed based on the Japanese classification of gastric cancer, such as undifferentiated adenocarcinoma. ${ }^{3}$ Undifferentiated adenocarcinoma in the Japanese classification includes poorly differentiated adenocarcinoma, SRC, and mucinous adenocarcinoma of the World Health Organization classification. Although biological behavior may differ among the histopathological subtypes of undifferentiated early gastric cancer (EGC), various treatment strategies have been applied indiscriminately to undifferentiated EGC, particularly ER.

In fact, the patterns of ER outcome differ between poorly differentiated adenocarcinoma and SRC, despite the subtypes in undifferentiated EGC. ${ }^{4}$ We previously reported an analysis of the clinicopathological outcomes of ER in undifferentiated EGC with special reference to histopathological subtypes. ${ }^{4}$

According to that study, all histologically incomplete resections in poorly differentiated adenocarcinoma were vertical cut end-positive, whereas almost all of the resections in SRC were lateral cut end-positive. ${ }^{4}$ That is, intramucosal lesions consisted of SRC may prefer horizontal spread to vertical spread. Furthermore, another message from these results was that endoscopic examination of the gross margin may lead to frequent underestimation of the true histopathological margins of SRC lesions. ${ }^{4}$

This discrepancy between the endoscopic and pathological margins of the lesion may be due to the different origins of SRC compared to other gastric adenocarcinomas. ${ }^{5}$ Tubule neck dysplasia (TND) may be a precursor lesion of SRC. TND can spread

Correspondence to: Jie-Hyun Kim

Department of Internal Medicine, Gangnam Severance Hospital, Yonsei University College of Medicine, 211 Eonju-ro, Gangnam-gu, Seoul 06273, Korea

Tel: +82-2-2019-3310, Fax: +82-2-3463-3882, E-mail: otilia94@yuhs.ac

Received on May 30, 2014. Revised on July 22, 2014. Accepted on July 23, 2014. Published online December 5, 2014

pISSN 1976-2283 eISSN 2005-1212 http://dx.doi.org/10.5009/gnl14203

(a) This is an Open Access article distributed under the terms of the Creative Commons Attribution Non-Commercial License (http://creativecommons.org/licenses/by-nc/4.0) which permits unrestricted non-commercial use, distribution, and reproduction in any medium, provided the original work is properly cited. 
upwards towards the foveolar surface and possibly downwards to the gastric glands. ${ }^{5}$ Thus, the gastric mucosa of SRC may show a largely intact surface epithelium, despite the presence of cancer cells in the lamina propria.

An analysis about intramucosal spreading patterns in SRC may be helpful for ER in SRC. Therefore, the aim of the study was to classify intramucosal spreading patterns of SRC and to analyze clinicopathological findings according to the spreading patterns.

\section{MATERIALS AND METHODS}

\section{Study subjects}

In total, 100 specimens from patients diagnosed with intramucosal lesions consisted of SRC and who underwent surgery at Severance Hospital, Yonsei University College of Medicine, Seoul, Korea, between January 2000 and February 2003 were reviewed. We also reviewed 42 ER specimens obtained between February 2003 and December 2010. All lesions were treated by endoscopic submucosal dissection (ESD) at Severance Hospital, and were mucosal-confined SRC. Lesions treated by endoscopic mucosal resection were excluded to decrease the mechanical factors in margin positivity.

The tumor size was measured using endoscopy and endoscopic ultrasonography. Lymph node or distant metastasis was evaluated by abdominal ultrasonography or computed tomography. The tumor locations were categorized by longitudinal axis and cross-sectional circumference of the stomach. That is, the longitudinal axis of the stomach was divided into three sections (the upper third containing the fundus, cardia, and upper body, the middle third containing the midbody, lower body, and angle, and the lower third containing the antrum and pylorus), and the cross-sectional circumference into four sections (lesser curvature, posterior wall, greater curvature, and anterior wall). Endoscopic findings of the tumors were classified by predominant type according to the classification system of the Japanese Research Society for Gastric Cancer. The protruded type and superficial elevated type were classified as elevated type. The superficial flat type was classified as flat type, and the superficial depressed type and excavated type were classified as depressed type, based on a previous study. ${ }^{6}$ The color of tumor was evaluated based on the endoscopic findings such as whitish discoloration or yellow to pinkish similar to surrounding mucosa.

We compared the expanding and infiltrative types of intramucosal spreading patterns in terms of their clinicopathological features in surgical and ER specimens. In surgical specimens, lymph node metastasis was also included and in ER specimens, lateral margin status (i.e., the tumor involvement of the resection margin) and recurrence were included. The Institutional Review Board at Severance Hospital approved this study (IRB number: 4-2012-0472).

\section{Classification of intramucosal spreading patterns in early SRC}

We classified the intramucosal spreading patterns of SRC into expanding and infiltrative types, based on a previous study. ${ }^{7}$ The expanding type was defined as a tumor that had a margin that was clearly lined from the nonneoplastic mucosa, that is, epithelial spreading pattern (Fig. 1A). The infiltrative type was defined as a tumor that showed diffuse spreading tumor cells (Fig. 1B), that is, subepithelial spreading pattern. For ambiguous cases, we arbitrarily defined criteria for the infiltrative type as a case that showed both a more than $2 \mathrm{~mm}$ tumor-cell spread along the lamina propria of the deeper part of the nonneoplastic mucosa and infiltration in more than half of the tumor margin.
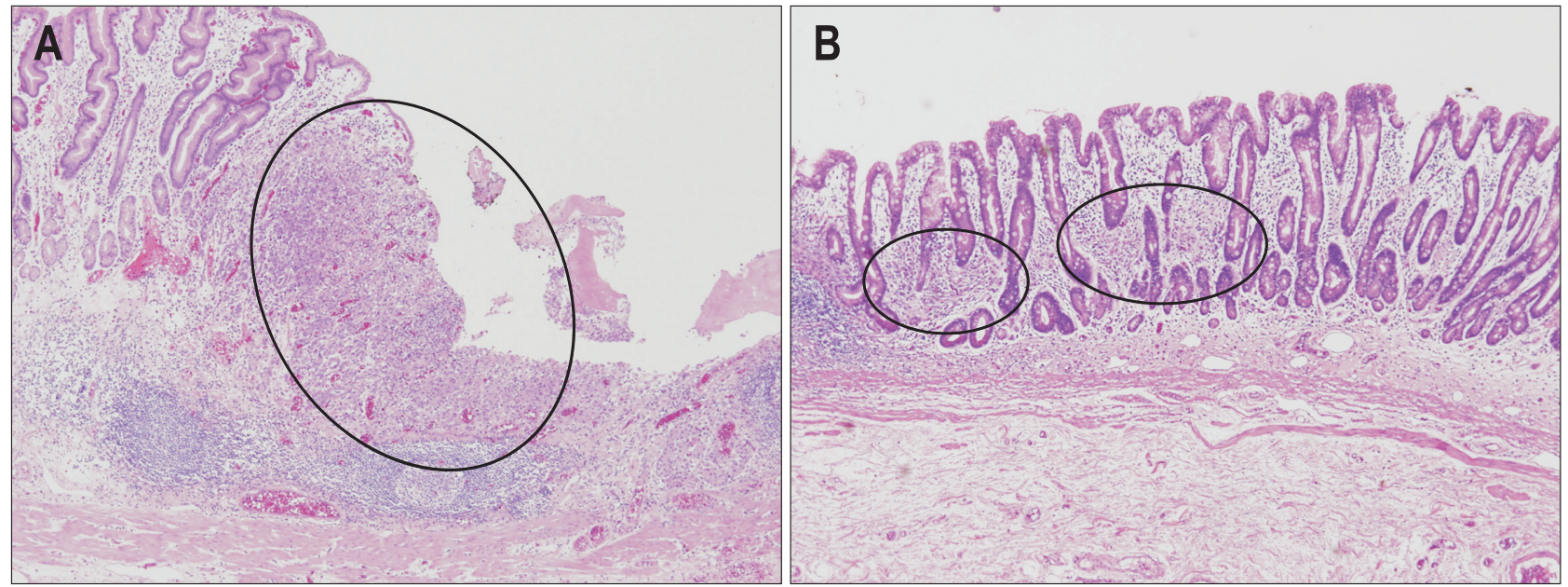

Fig. 1. Signet ring cell carcinoma intramucosal spreading types. Expansive type. (A) Tumor cells (circle) were exposed at a superficial part of the mucosa. A tumor with a margin was distinct from the nonneoplastic mucosa (H\&E stain, $\times 40)$. (B) Tumor cells (circles) were located in the intermediate or deeper parts of the nonneoplastic mucosa. Diffuse-spreading tumor cells were evident (H\&E stain, $\times 40$ ). 
Table 1. Comparison of the Intramucosal Spreading Patterns of Signet Ring Cell Carcinoma and Clinicopathological Characteristics of Surgical and Endoscopic-Resected Specimens

\begin{tabular}{|c|c|c|c|c|c|c|}
\hline \multirow{2}{*}{ Characteristic } & \multicolumn{2}{|c|}{$\begin{array}{l}\text { Intramucosal spreading patterns } \\
\text { (surgical specimen) }\end{array}$} & \multirow{2}{*}{ p-value } & \multicolumn{2}{|c|}{$\begin{array}{l}\text { Intramucosal spreading patterns } \\
\text { (endoscopic specimen) }\end{array}$} & \multirow{2}{*}{$\mathrm{p}$-value } \\
\hline & $\begin{array}{l}\text { Infiltrative } \\
(\mathrm{n}=56)\end{array}$ & $\begin{array}{l}\text { Expanding } \\
(\mathrm{n}=44)\end{array}$ & & $\begin{array}{l}\text { Infiltrative } \\
(\mathrm{n}=21)\end{array}$ & $\begin{array}{l}\text { Expanding } \\
(\mathrm{n}=21)\end{array}$ & \\
\hline Male sex & $30(53.6)$ & $17(38.6)$ & 0.137 & $5(23.8)$ & $11(52.4)$ & 0.054 \\
\hline Age, yr & $53.3 \pm 10.6$ & $46.9 \pm 13.1$ & 0.010 & $52.3 \pm 14.1$ & $54.0 \pm 13.0$ & 0.683 \\
\hline \multicolumn{3}{|l|}{ Gross appearance } & 0.790 & & & 0.770 \\
\hline Elevated & $1(1.8)$ & $1(2.3)$ & & $2(9.5)$ & $4(19.0)$ & \\
\hline Flat & $9(16.1)$ & $5(11.4)$ & & $10(47.6)$ & $8(38.1)$ & \\
\hline Depressed & $46(82.1)$ & $38(86.4)$ & & $9(42.9)$ & $9(42.9)$ & \\
\hline \multicolumn{3}{|l|}{ Longitudinal location } & 1.000 & & & 0.536 \\
\hline Upper third & $3(5.3)$ & $3(6.9)$ & & $1(4.8)$ & 0 & \\
\hline Middle third & $36(64.3)$ & $28(63.6)$ & & $12(57.1)$ & $10(47.6)$ & \\
\hline Lower third & $17(30.4)$ & $13(29.5)$ & & $8(38.1)$ & $11(52.4)$ & \\
\hline \multicolumn{3}{|l|}{ Cross-sectional location } & 1.000 & & & 0.571 \\
\hline Lesser curvature & $26(46.4)$ & $21(47.7)$ & & $8(38.1)$ & $5(23.8)$ & \\
\hline Posterior wall & $13(23.2)$ & $10(22.7)$ & & $2(9.5)$ & $5(23.8)$ & \\
\hline Greater curvature & 7 (12.5) & $5(11.4)$ & & $7(33.4)$ & 6 (28.6) & \\
\hline Anterior wall & $10(17.9)$ & $8(18.2)$ & & $4(19.0)$ & $5(23.8)$ & \\
\hline \multicolumn{3}{|l|}{ Color of the tumor } & 0.225 & & & 1.000 \\
\hline Whitish discoloration & $20(35.7)$ & $21(47.7)$ & & $12(57.1)$ & $12(57.1)$ & \\
\hline Yellowish to pinkish* & $36(64.3)$ & $23(52.3)$ & & $9(42.9)$ & $9(42.9)$ & \\
\hline Ulcer & $16(28.6)$ & $10(22.7)$ & 0.508 & $2(9.5)$ & $3(14.3)$ & 1.000 \\
\hline LVI & $1(1.8)$ & $2(4.5)$ & 0.581 & $1(4.8)$ & 0 & \\
\hline LNM & $3(5.4)$ & $2(4.5)$ & 1.000 & - & - & \\
\hline Size, $\mathrm{mm}$ & $23.9 \pm 14.8$ & $26.2 \pm 18.8$ & 0.494 & $17.9 \pm 10.0$ & $10.3 \pm 5.7$ & 0.005 \\
\hline Lateral margin (+) & - & - & & 6 (28.6) & $2(9.5)$ & 0.238 \\
\hline Residual tumor & - & - & & $2(9.5)$ & 0 & 0.488 \\
\hline Recurrence & 0 & $1(2.3)$ & 0.689 & $1(4.8)$ & 0 & 1.000 \\
\hline H. pylori infection & $28(50.0)$ & $32(72.7)$ & 0.021 & 7 (33.3) & $9(42.9)$ & 0.525 \\
\hline \multicolumn{3}{|l|}{ Atrophy } & $<0.001$ & & & 0.050 \\
\hline Absent & $23(41.1)$ & $35(79.5)$ & & $11(52.4)$ & $17(81.0)$ & \\
\hline Mild & $6(10.7)$ & $5(11.4)$ & & - & - & \\
\hline Moderate & $11(19.6)$ & $1(2.3)$ & & 10 (47.6) & $4(19.0)$ & \\
\hline Severe & $16(28.6)$ & $3(6.8)$ & & - & - & \\
\hline \multicolumn{3}{|l|}{ Intestinal metaplasia } & 0.001 & & & 0.050 \\
\hline Absent & $18(32.1)$ & $27(61.4)$ & & \multirow{2}{*}{$11(52.4)$} & \multirow{2}{*}{$17(81.0)$} & \\
\hline Mild & $13(23.2)$ & $12(27.3)$ & & & & \\
\hline Moderate & 7 (12.5) & $3(6.8)$ & & \multirow{2}{*}{$10(47.6)$} & \multirow{2}{*}{$4(19.0)$} & \\
\hline Severe & $18(32.2)$ & $2(4.5)$ & & & & \\
\hline \multicolumn{2}{|c|}{ Lymphoplasmacytic cell infiltration $^{\dagger}$} & & 0.461 & & & 0.378 \\
\hline Absent/mild & $5(8.9)$ & $2(4.5)$ & & $4(19.0)$ & $2(9.5)$ & \\
\hline Moderate/severe & $51(91.1)$ & $42(95.5)$ & & $17(81.0)$ & $19(90.5)$ & \\
\hline Neutrophil infiltration ${ }^{\dagger}$ & & & 0.302 & & & 0.050 \\
\hline Absent/mild & $30(53.6)$ & $19(43.2)$ & & 17 (81.0) & $11(52.4)$ & \\
\hline Moderate/severe & $26(46.4)$ & $25(56.8)$ & & $4(19.0)$ & 10 (47.6) & \\
\hline
\end{tabular}

Data are presented as number (\%) or mean \pm SD.

LVI, lymphovascular invasion; LNM, lymph node metastasis; H. pylori, Helicobacter pylori.

*Similar to the surrounding mucosa; ${ }^{\dagger}$ Cell infiltration was graded as absent/mild or moderate/severe according to the updated Sydney System. 


\section{Histological analysis of adjacent nonneoplastic mucosa}

We retrospectively assessed the histology of the adjacent mucosa in terms of Helicobacter pylori infection, glandular atrophy, intestinal metaplasia (IM), lymphoplasmacytic cell infiltration (chronic inflammation), and neutrophilic infiltration, based on the updated Sydney System. ${ }^{8}$ Glandular atrophy and the IM were graded as absent, mild, moderate, or severe according to the updated Sydney System. The status of $H$. pylori infection was classified as present or absent in the ER specimens. The status of $H$. pylori infection was evaluated from histological examination and other clinical records. Lymphoplasmacytic cell and neutrophilic infiltration were graded as absent/mild or moderate/severe.

In the surgical series, the adjacent mucosa was defined as near $(<5 \mathrm{~mm})$ the tumor margin and in the ER specimens, the adjacent mucosa was defined as all of the resected nonneoplastic mucosa.

\section{Statistics}

The chi-square test and Fisher exact test were used to evaluate associations among various categorical variables, and the ttest was used for noncategorical variables. A p-value $<0.05$ was considered to indicate statistical significance. All analyses were performed using the SPSS software version 18.0 (SPSS Inc., Chicago, IL, USA).

\section{RESULTS}

\section{Comparisons between intramucosal spreading patterns of SRC and clinicopathological characteristics in surgi- cal and ER specimens}

The proportions of the expansive and infiltrative types in the surgical specimens were $44 \%$ and 56\%, respectively. Gender, endoscopic gross appearance, size, lymphovascular invasion, lymph node metastasis, and recurrence rate were not significantly different between the two types (Table 1). However, the infiltrative type was more commonly associated with old age, atrophy, and IM in the surrounding mucosa, and absence of $H$. pylori than was the expansive type.

With the infiltrative type, the adjacent mucosa showed significantly more severe atrophy and IM compared to the expanding type. However, there was no significant difference in terms of lymphoplasmacytic cell infiltration or neutrophilic infiltration between the two types.

The proportions of the expansive and infiltrative types were 50\% and 50\% in ESD specimens, similar to the surgical specimens. Larger size was significantly associated with the infiltrative type. Similar to the surgical specimens, atrophy and IM in the surrounding mucosa, and lack of neutrophil infiltration were observed more commonly in the infiltrative type than the expansive type in spite of statistical insignificance (Table 1).
Table 2. Comparison of Lateral Margin-Positive and -Negative Lesions in Endoscopic-Resected Specimens

\begin{tabular}{|c|c|c|c|}
\hline Characteristic & $\begin{array}{c}\underset{(\mathrm{n}=8)}{\operatorname{Margin}}(+) \\
\end{array}$ & $\begin{array}{c}\text { Margin }(-) \\
(\mathrm{n}=34)\end{array}$ & $\mathrm{p}$-value \\
\hline Male & $1(12.5)$ & $15(44.1)$ & 0.127 \\
\hline Age, yr & $53.6 \pm 15.1$ & $53.0 \pm 13.2$ & 0.920 \\
\hline Gross appearance & & & 1.000 \\
\hline Elevated & $1(12.5)$ & $5(14.7)$ & \\
\hline Flat & $4(50.0)$ & $14(41.2)$ & \\
\hline Depressed & $3(37.5)$ & $15(44.1)$ & \\
\hline Longitudinal location & & & 0.082 \\
\hline Upper third & 0 & $1(2.9)$ & \\
\hline Middle third & $7(87.5)$ & $15(44.1)$ & \\
\hline Lower third & $1(12.5)$ & $18(53.0)$ & \\
\hline Cross-sectional location & & & 0.720 \\
\hline Lesser curvature & $4(50.0)$ & $9(26.5)$ & \\
\hline Posterior wall & $1(12.5)$ & $6(17.6)$ & \\
\hline Greater curvature & $2(25.0)$ & $11(32.4)$ & \\
\hline Anterior wall & $1(12.5)$ & $8(23.5)$ & \\
\hline Color of the tumor & & & 0.473 \\
\hline Whitish discoloration & $4(50.0)$ & $20(58.8)$ & \\
\hline Yellowish to pinkish* & $4(50.0)$ & $14(41.2)$ & \\
\hline Ulcer & 0 & $5(14.7)$ & 0.564 \\
\hline LVI & 0 & $1(2.9)$ & 1.000 \\
\hline Size, $\mathrm{mm}$ & $22.5 \pm 12.3$ & $12.1 \pm 6.8$ & 0.049 \\
\hline Residual lesion & $2(25.0)$ & 0 & 0.033 \\
\hline H. pylori infection & $2(25.0)$ & $14(41.2)$ & 0.688 \\
\hline Intramucosal type & & & 0.119 \\
\hline Infiltrative & $6(75.0)$ & $15(44.1)$ & \\
\hline Expanding & $2(25.0)$ & 19 (55.9) & \\
\hline Atrophy & & & 0.406 \\
\hline Absent/mild & $4(50.0)$ & 24 (70.6) & \\
\hline Moderate/severe & $4(50.0)$ & $10(29.4)$ & \\
\hline Intestinal metaplasia & & & 1.000 \\
\hline Absent/mild & $5(62.5)$ & $23(67.6)$ & \\
\hline Moderate/severe & $3(37.5)$ & $11(32.4)$ & \\
\hline \multicolumn{2}{|c|}{ Lymphoplasmacytic cell infiltration $^{\dagger}$} & & 0.319 \\
\hline Absent/mild & $2(25.0)$ & $4(11.8)$ & \\
\hline Moderate/severe & $6(75.0)$ & $30(88.2)$ & \\
\hline Neutrophil infiltration $^{\dagger}$ & & & 0.037 \\
\hline Absent/mild & $8(100.0)$ & $20(58.8)$ & \\
\hline Moderate/severe & 0 & $14(41.2)$ & \\
\hline
\end{tabular}

Data are presented as number $(\%)$ or mean \pm SD.

LVI, lymphovascular invasion; H. pylori, Helicobacter pylori.

"Similar to the surrounding mucosa; ${ }^{\dagger}$ Cell infiltration was graded as absent/mild or moderate/severe according to the updated Sydney System. 
Lateral margin-positive lesions were more commonly observed in the infiltrative type than the expanding type, although the difference was not statistically significant. Recurrent case after ESD was of the infiltrative type.

When lateral margin-positive lesions were compared with negative lesions in ESD specimens, larger size, residual lesion, and lack of neutrophil infiltration were more significantly associated with lateral margin-positive lesions (Table 2). All cases with residual tumors in lateral margin-positive lesions were of the infiltrative type.

\section{Clinical cases according to intramucosal spreading pat- terns of SRC}

1) Expanding intramucosal spreading type of early SRC (Fig. 2)

A 15-mm depressed lesion was found at the posterior wall of the lower body, confirmed as SRC by biopsy. Endoscopically, the surrounding mucosa was not combined with atrophic gastritis or IM. The lesion was resected by ESD, and the pathologic report was as follows: (1) Location: body, posterior wall; (2) Gross type: EGC type IIc; (3) Histologic type: signet-ring cell carcinoma; (4) Histologic type by Lauren: diffuse; (5) Size: $1.3 \times 0.9 \mathrm{~cm}$; (6) Depth of invasion: lamina propria (pT1a); (7) Resection margin: free from carcinoma (safety margin: distal $1 \mathrm{~cm}$, proximal $1.2 \mathrm{~cm}$, anterior $0.5 \mathrm{~cm}$, posterior $0.6 \mathrm{~cm}$ ); (8) Lymphovascular invasion: not identified; (9) Perineural invasion: not identified.

Pathological findings showed the expanding intramucosal spreading type. The patient was followed up over 5 years without recurrence.

\section{2) Infiltrative intramucosal spreading type of early SRC (Fig. 3)}

Before ER, a tiny erythematous flat lesion was found at
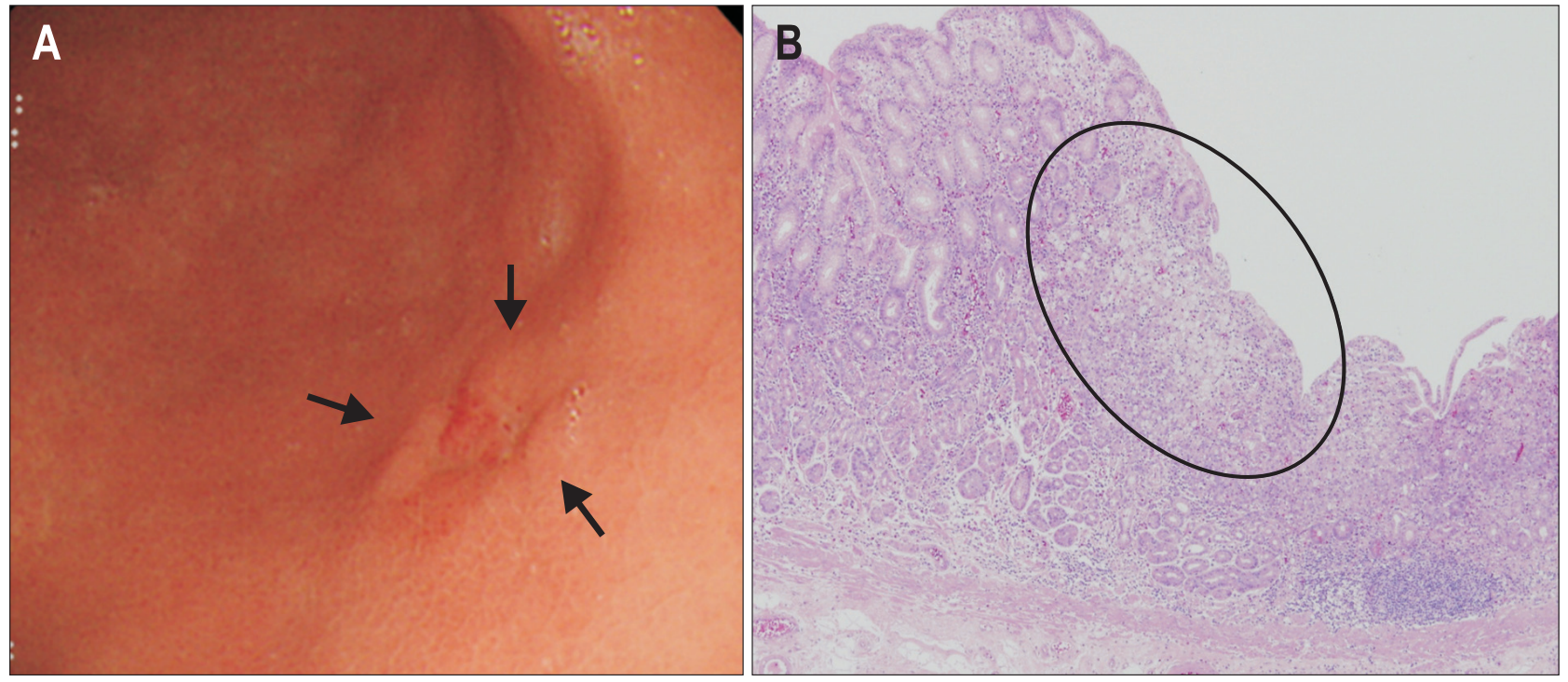

Fig. 2. Clinical case of the expanding intramucosal-spreading type of signet ring cell carcinoma (SRC). (A) Endoscopic image of early gastric cancer revealing a depressed lesion located in the posterior wall of the lower body (arrows). Endoscopically, the surrounding mucosa was not combined with atrophy or intestinal metaplasia. (B) Pathological findings after endoscopic resection (H\&E stain, $\times 40)$. Tumor cells of the SRC were exposed at a superficial part of the mucosa and were well demarcated (circle).
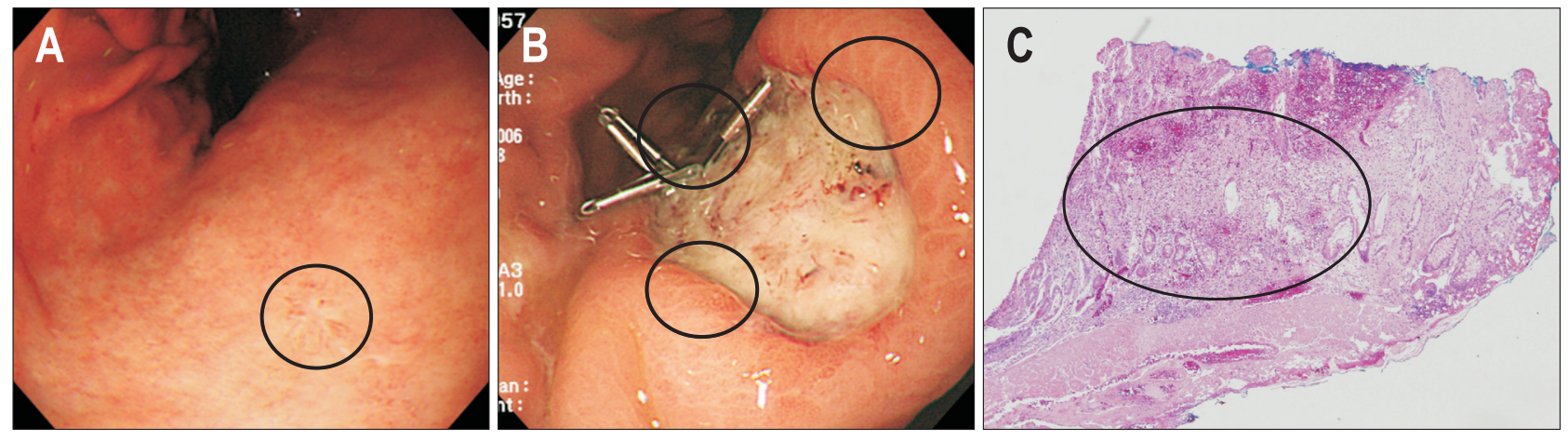

Fig. 3. Clinical case of the infiltrative intramucosal-spreading type of signet ring cell carcinoma (SRC). (A) Endoscopic image of early gastric cancer showing a flat lesion located in the lesser curvature of the lower body (circle). Endoscopically, the surrounding mucosa was combined with atrophic gastritis. (B) After endoscopic resection, three lateral margins were positive (circles). (C) Pathological findings after endoscopic resection (H\&E stain, $\times 40$ ). SRC cells exhibited subepithelial spread, indicating that the lesion was of the infiltrative type (circle). 
the lesser curvature of the lower body, and the diagnosis was confirmed as SRC by biopsy. Endoscopically, the surrounding mucosa was combined with atrophic gastritis. The lesion was resected by ESD, and the pathologic report was as follows: (1) Location: body, lesser curvature; (2) Gross type: EGC type IIc+IIb; (3) Histologic type: signet ring cell carcinoma; (4) Histologic type by Lauren: diffuse; (5) Size: $2.5 \times 1.5 \mathrm{~cm}$; (6) Depth of invasion: invades mucosa (lamina propria) (pT1a); (7) Resection margins: Lateral (proximal, anterior, posterior margin): involved by carcinoma; Basal: free from carcinoma; (8) Lymphovascular invasion: not identified; (9) Perineural invasion: not identified.

Thus, additional surgery was performed after ESD, and residual cancer cells were found in the surgical specimen without lymph node metastasis. The intramucosal spreading pattern was of the infiltrative type.

\section{DISCUSSION}

Based on expanded indications, ER has provided many EGC patients the opportunity to preserve their stomach. A recent large-scale study revealed that the expanded indications, excluding undifferentiated EGC, resulted in overall survival and local tumor recurrence rates that were similar to those of the standard indications for ER in EGC. ${ }^{9}$ In undifferentiated EGC, long-term outcomes after ER have been reported despite the small numbers of subjects. ${ }^{10,11}$ According to these studies, ER for undifferentiated EGC may yield good long-term outcomes.

Horizontal growth pattern and subepithelial spread may be representative features of intramucosal lesions consisted of SRC. ${ }^{4,5}$ These may cause the margins of SRC lesions to be obscure, as seen in ER outcomes. ${ }^{4}$ Advanced endoscopic techniques such as magnifying endoscopy (ME) with narrow-band imaging (NBI) can assist definition of the exact margins of lesions. ${ }^{12,13}$ However, even using ME with NBI, endoscopic delineation remains difficult for undifferentiated lesions, according to a recent study. ${ }^{12}$ This is likely due to subepithelial spread of intramucosal lesions consisted of SRC. Thus, definition of epithelial spread subgroups is critical to clarifying the need for local treatment of SRC.

A previous study reported two types of intramucosal spreading patterns in SRC, the expansive and infiltrative types. ${ }^{7}$ The expansive type is defined as tumor exposure at a superficial part of the mucosa, unlike the infiltrative type. ${ }^{7}$ Theoretically, the infiltrative type may be the risk group of noncurative resection by ESD in SRC. Thus, we investigated the feasibility of classification of intramucosal lesions consisted of SRC in terms of intramucosal spreading patterns, such as expansive and infiltrative types, in surgical and ER specimens. According to our data, the proportions of the expansive and infiltrative types were $44 \%$ and 56\%, and 50\% and 50\% in surgical and ESD specimens, respectively. This indicates the feasibility of subgrouping based on intramucosal spreading patterns is appropriate in intramucosal lesions consisted of SRC.

In fact, the positive rate of lateral margins in ESD specimens was higher in the infiltrative type than the expanding type, although the difference was not statistically significant due to the small number of subjects. After additional resection of lateral margin-positive lesions, all of those with residual tumor cells were of the infiltrative type.

The surrounding mucosal pattern differed between the expanding and infiltrative types. The mucosa surrounding infiltrative-type lesions was more commonly associated with atrophy and IM, absence of $H$. pylori, and a lack of neutrophil infiltration. This indicates that the surrounding mucosa may be important as a mechanical barrier to tumor cell spread in SRC. If mechanical barrier represented by the surrounding mucosa is weak, such as due to atrophy/IM or no neutrophil infiltration, tumor cells tend to spread sporadically or diffusely into the deeper part of the mucosa. However, in such cases, tumor cells tend to be exposed at the superficial mucosa; e.g., in an expanding spreading-type lesion with an intact mechanical barrier. Thus, the status of the surrounding mucosa can be predictive of the intramucosal spreading patterns in SRC. However, this should be validated by large scale study in the future.

Further investigations of molecular markers expressed in tumor cells and the surrounding mucosa may assist prediction of intramucosal spread patterns in SRC.

Intramucosal spreading patterns and the status of the surrounding mucosa may be important in synchronous or metachronous cancers in SRC. Generally, synchronous or metachronous EGC has been reported more in differentiated than undifferentiated EGC. ${ }^{14,15}$ This is a consequence of intestinal-type gastric carcinogenesis. Intestinal-type gastric cancer is derived from a series of sequential pathological events according to Correa's cascade. ${ }^{16}$ That is, the surrounding mucosa in intestinaltype gastric cancer is the milieu for generation of premalignant lesions or dysplasia. However, the mucosa surrounding SRC lesions may be important for synchronous or metachronous lesions. The status of the surrounding mucosa, such as atrophy/ IM, can provide the milieu for sporadic spreading of tumor cells because of the weak mechanical barrier. In fact, synchronous and metachronous EGC are common in undifferentiated EGC. ${ }^{17}$ However, in the present study, there was no synchronous or metachronous SRC during the follow-up period. Thus, intramucosal spreading patterns according to synchronous or metachronous SRC could not be investigated. However, the analysis of intramucosal spreading patterns may assist discrimination of synchronous and metachronous SRC.

Although our study included almost pure SRC, not combined with other histologies, SRC can coexist with other histologies. Mixed histology has been known to show more aggressive behavior such as deeper invasion or higher rate of lymph node metastasis than others. However, we investigated the intramucosal spreading patterns at the margin of the lesions, so our 
results might apply to the lesions combined with small amount of other histologies if the histology at the margin is SRC. But, further study among the mixed histologies should be necessary in the future.

In conclusion, the analysis of intramucosal spreading patterns in SRC is helpful for ER in SRC. Intramucosal spreading patterns in SRC may be dependent on the surrounding mucosa. SRC surrounded with atrophy or/and intestinal metaplasia often spread subepithelially in the margin. It may suggest that larger safety margin is necessary in this type during ESD.

\section{CONFLICTS OF INTEREST}

No potential conflict of interest relevant to this article was reported.

\section{ACKNOWLEDGEMENTS}

This research was supported by the Basic Science Research Program through the National Research Foundation of Korea (NRF), funded by the Ministry of Education, Science, and Technology (2012R1A1A1042417).

\section{REFERENCES}

1. Gotoda T, Yanagisawa A, Sasako M, et al. Incidence of lymph node metastasis from early gastric cancer: estimation with a large number of cases at two large centers. Gastric Cancer 2000;3:219225.

2. Hirasawa T, Gotoda T, Miyata S, et al. Incidence of lymph node metastasis and the feasibility of endoscopic resection for undifferentiated-type early gastric cancer. Gastric Cancer 2009;12:148152.

3. The general rules for the gastric cancer study in surgery ad pathology. Part II. Histological classification of gastric cancer. Jpn J Surg 1981;11:140-145.

4. Kim JH, Lee YC, Kim H, et al. Endoscopic resection for undifferentiated early gastric cancer. Gastrointest Endosc 2009;69:e1-e9.

5. Kumarasinghe MP, Lim TK, Ooi CJ, Luman W, Tan SY, Koh M. Tubule neck dysplasia: precursor lesion of signet ring cell carcinoma and the immunohistochemical profile. Pathology 2006;38:468-
471.

6. Akahoshi K, Chijiwa Y, Hamada S, et al. Pretreatment staging of endoscopically early gastric cancer with a $15 \mathrm{MHz}$ ultrasound catheter probe. Gastrointest Endosc 1998;48:470-476.

7. Aihara R, Mochiki E, Kamiyama Y, Kamimura H, Asao T, Kuwano $\mathrm{H}$. Mucin phenotypic expression in early signet ring cell carcinoma of the stomach: its relationship with the clinicopathologic factors. Dig Dis Sci 2004;49:417-424.

8. Dixon MF, Genta RM, Yardley JH, Correa P. Classification and grading of gastritis. The updated Sydney System. International Workshop on the Histopathology of Gastritis, Houston 1994. Am J Surg Pathol 1996;20:1161-1181.

9. Isomoto H, Shikuwa S, Yamaguchi N, et al. Endoscopic submucosal dissection for early gastric cancer: a large-scale feasibility study. Gut 2009;58:331-336.

10. Kamada K, Tomatsuri N, Yoshida N. Endoscopic submucosal dissection for undifferentiated early gastric cancer as the expanded indication lesion. Digestion 2012;85:111-115.

11. Okada K, Fujisaki J, Yoshida T, et al. Long-term outcomes of endoscopic submucosal dissection for undifferentiated-type early gastric cancer. Endoscopy 2012;44:122-127.

12. Nagahama T, Yao K, Maki S, et al. Usefulness of magnifying endoscopy with narrow-band imaging for determining the horizontal extent of early gastric cancer when there is an unclear margin by chromoendoscopy (with video). Gastrointest Endosc 2011;74:1259-1267.

13. Hirata I, Nakagawa Y, Ohkubo M, Yahagi N, Yao K. Usefulness of magnifying narrow-band imaging endoscopy for the diagnosis of gastric and colorectal lesions. Digestion 2012;85:74-79.

14. Nitta T, Egashira Y, Akutagawa H, et al. Study of clinicopathological factors associated with the occurrence of synchronous multiple gastric carcinomas. Gastric Cancer 2009;12:23-30

15. Han JS, Jang JS, Choi SR, et al. A study of metachronous cancer after endoscopic resection of early gastric cancer. Scand J Gastroenterol 2011;46:1099-1104.

16. Correa P. A human model of gastric carcinogenesis. Cancer Res 1988;48:3554-3560.

17. Seo JH, Park JC, Kim YJ, Shin SK, Lee YC, Lee SK. Undifferentiated histology after endoscopic resection may predict synchronous and metachronous occurrence of early gastric cancer. Digestion 2010;81:35-42. 